\title{
Asymmetry of brain structure and function: 40 years after Sperry's Nobel Prize
}

\author{
Michel Thiebaut de Schotten ${ }^{1,2} \cdot$ Christian F. Beckmann ${ }^{3,4}$
}

Published online: 15 November 2021

(c) The Author(s), under exclusive licence to Springer-Verlag GmbH Germany, part of Springer Nature 2021

Since Roger Sperry's Nobel Prize (1981; see also Sperry 1974) for his discoveries of the functional specialisation of the cerebral hemispheres, significant theoretical and methodological advances have improved the quantitative characterisation of functional and structural markers of brain asymmetries. For instance, we now know that this is the disproportionate increase in brain size that led human brain evolution to distribute functions unevenly between the left and the right hemispheres (Ringo et al. 1994; Vallortigara and Rogers 2005; Karolis et al. 2019) to optimise brain processing time (Ringo et al. 1994). However, this hemispheric functional specialisation is at the expense of resilience against brain injury (Forkel et al. 2014; Bartolomeo and Thiebaut de Schotten 2016).

With the present special issue, we wish to celebrate the 40th anniversary of Sperry's prime scientific distinction with an update on the vision of the brain structure and function asymmetry. A prestigious list of authors submitted their original article, reviews and viewpoints on the link between the asymmetry of structure and function, their presentation across different species, and their development and variability across participants.

We live in an exciting time as computer algorithms can help us sharpen our observation and accelerate scientific

Michel Thiebaut de Schotten

michel.thiebaut@gmail.com

1 Groupe d'Imagerie Neurofonctionnelle, Institut des Maladies Neurodégénératives-UMR 5293, CNRS, CEA, University of Bordeaux, Bordeaux, France

2 Brain Connectivity and Behaviour Laboratory, Sorbonne Universities, Paris, France

3 Donders Institute for Brain, Cognition and Behaviour, Radboud University Medical Center, Nijmegen, The Netherlands

4 Centre for Functional MRI of the Brain (FMRIB), Nuffield Department of Clinical Neurosciences, Wellcome Centre for Integrative Neuroimaging, University of Oxford, Oxford, UK work. A prime example of the utility of such advances is the report of Friedrich et al. (Friedrich et al. in press; this issue), who applied machine learning to automatically discriminate magnetic resonance imaging of the left human hemisphere from the right with great accuracy $(>95 \%)$. Whilst this advance will have some critical use in neuroimaging, it also highlights fundamental structural differences between the left and the right hemispheres.

Some structural differences are apparent such as the anticlockwise deformation of the base of the brain (i.e. right frontal lobe pushing the left and left occipital lobe pushing the right Hadziselimovic and Ruzdic (1966), Toga and Thompson (2003)), the Yakovlevian torque of the pyramidal tract (Yakovlev and Rakic 1966), and the wider left planum temporale (Wada et al. 1975; Geschwind and Levitsky 1968). Other differences are more discreet such as the asymmetry of the posterior portion of the inferior frontal gyrus-Broca Area-that presents with left microstructural differences (Sprung-Much et al. 2021; this issue). However, not all the brain is asymmetrical. For instance, subcortical structures are symmetrical even in older participants (Gomez-Ramirez and Gonzalez-Rosa 2021; this issue).

Comparisons across species demonstrated that these asymmetries are not unique to humans and exist in other non-human primates, albeit proportional to brain size (see Gonzalez et al. in press; this issue for an investigation of several new-world monkeys species). Accordingly, language-specific areas, such as the planum temporale, are leftward asymmetric in the old world (Becker et al. 2021; this issue) and the new-world monkeys (Gonzalez et al. in press; this issue). Further, brain asymmetries already exist in newborn primates (Becker et al. 2021; this issue), preterm humans (Bisiacchi and Cainelli 2021; this issue) and chick embryos, demonstrating a potentially important role of asymmetrical embryonic stimulation in brain structural and functional symmetry (Costalunga et al. 2021; this issue). However, to our knowledge, none of the non-human primates present with elaborated language abilities; therefore, 
brain structural asymmetries may not reflect language dominance (Sprung-Much et al. 2021; this issue). Similarly, while polygenic scores are significantly associated with handedness genes, brain structural asymmetries (surface, volume or thickness) are not (Ocklenburg et al. 2021; this issue).

It might be that the relationship between structure and function asymmetries is hidden by a large interindividual variability (Thiebaut de Schotten and Shallice 2017; Mazoyer et al. 2014; Thiebaut de Schotten et al. 2019; Vingerhoets 2019; Borghei et al. 2021; this issue, Forkel et al. 2021; this issue, Westerhausen and Papadatou-Pastou in press; this issue) or that the brain structural measurements investigated are too broad (Sprung-Much et al. 2021; this issue) or that functions are not organised in the brain as we think of it (Thiebaut de Schotten et al. 2020).

Regarding interindividual variability, our special issue demonstrates that a better characterisation of the populationlevel functional lateralisation yields a more straightforward relationship to function. A prime example is Guadalupe et al. (Guadalupe et al. 2021; this issue), who used a dichotic listening task to characterise precisely the level of left-hemispheric dominance for speech processing. Accordingly, most of us are left dominant, but not all, as 1/4 of the healthy population would be dominant for the right hemisphere; while the remaining $11 \%$ are bilateral. These numbers are much higher than the prevalence of frontal operculum, and planum temporale asymmetries initially reported Wada (1975), confirming that these are not directly related to language dominance. Instead, Guadalupe et al. (2021; this issue) indicate that hemispheric dominance in speech processing is statistically associated with asymmetries in volume in the amygdala, posterior portion of the superior temporal gyrus, and lobule VI of the cerebellum. Similarly, within left-handed structural differences exist between participants with right hemispheric language dominance and typically left lateralised but this time in the insula and the inferior frontal gyrus (Gerrits et al. 2021; this issue). The stages of brain development may also influence these results. For instance, early stages of literacy acquisition come in pairs with larger left fusiform gyrus size, while later stages show no difference (Beelen et al. 2021; this issue). These changes in the fusiform gyrus are independent of the functional lateralisation of the right fusiform gyrus for faces (Rossion and Lochy 2021; this issue). Hence, these studies demonstrate that the association between structural and functional asymmetries might not be the same across the population according to their brain phenotype and their stages of brain development (as previously suggested in Vingerhoets 2019; Vallortigara and Rogers 2005; McManus 2002).

Sharper brain measures also yield more encouraging results. For instance, the location of fine sulci in the left frontal lobe corresponds to differences in the location of the language-related functional activity (movement of the lips, tongue, and larynx, Eichert et al. 2021; this issue). Exploring the circuitry supporting the interaction between brain areas might also be better suited to studying the relationship between brain structure and function than the investigation of single areas (Takemura and Thiebaut de Schotten 2020). Accordingly, Gonzalez Alam et al. (2021; this issue) report that hemispheric difference in functional connectivity is associated with more accurate semantic performance for the left hemisphere and visual reasoning in the right hemisphere. Lower connectivity between the hemisphere is also associated with better multitasking (i.e. reduced switching costs, Vallesi et al. 2021; this issue). These two studies suggest that fine-tuned structural differences between the hemispheres allow for better cognitive performance. Most importantly, fine measures are usually neglected in automatised analyses, and when they are not, $30 \%$ of these studies forgot to mention the hemisphere concerned with the statistical differences (Forkel et al. 2021; this issue).

However, for those studies that do specify the hemisphere, almost twice as more studies are reporting a correlation between white matter structure and function in the left hemisphere than in the right hemisphere (Forkel et al. 2021; this issue). Such asymmetry in the structure-function relationship might be because we know the functions of the right hemisphere much less than the left (Thiebaut de Schotten et al. 2020). As reviewed by Palomero-Gallagher and Amunts (2021; this issue), emotional processing, which is traditionally associated with the right hemisphere (Mills 1912; Ioannucci et al. 2020; Borod 1993; Silberman and Weingartner 1986; Gainotti 2019), can be divided into subcomponents (i.e. generation, perception, and regulation) which do not necessarily share the same lateralisation patterns. Other functions such as visual imagery are dominant in the left hemisphere for orthographic images and in the right for exogenous stimuli (Liu et al. 2021; this issue). Some other functions do not even have an exact name or definition, such as the right hemispheric orchestration of oscillatory patterns to support visual processing (Gallina et al. 2021; this issue). Hence, a significant amount of work is still required to polish the functional fabric of the human mind as we understand it before we can assess their functional and structural lateralisation comprehensively and with satisfying accuracy.

Overall, substantial progress in the study of functional and structural markers of brain asymmetries has been achieved since Roger Sperry was awarded the Nobel Prize. However, new challenges arise with each discovery, such as better characterising brain functions and defining what constitutes a functionally meaningful structural unit. The following 40 years will be challenging indeed, but exciting! 
Acknowledgements We wish to thank Stephanie J Forkel for reading the first draft of this editorial and for her helpful comments.

\section{References}

Bartolomeo P, Thiebaut de Schotten M (2016) Let thy left brain know what thy right brain doeth: inter-hemispheric compensation of functional deficits after brain damage. Neuropsychologia. https:// doi.org/10.1016/j.neuropsychologia.2016.06.016

Becker Y, Phelipon R, Sein J, Velly L, Renaud L, Meguerditchian A (2021) Planum temporale grey matter volume asymmetries in newborn monkeys (Papio anubis). Brain Struct Funct. https:// doi.org/10.1007/s00429-021-02278-9

Beelen C, Blockmans L, Wouters J, Ghesquiere P, Vandermosten M (2021) Brain-behavior dynamics between the left fusiform and reading. Brain Struct Funct. https://doi.org/10.1007/ s00429-021-02372-y

Bisiacchi P, Cainelli E (2021) Structural and functional brain asymmetries in the early phases of life: a scoping review. Brain Struct Funct. https://doi.org/10.1007/s00429-021-02256-1

Borghei A, Piracha A, Sani S (2021) Prevalence and anatomical characteristics of the human massa intermedia. Brain Struct Funct 226(2):471-480. https://doi.org/10.1007/s00429-020-02193-5

Borod JC (1993) Cerebral mechanisms underlying facial, prosodic, and lexical emotional expression: a review of neuropsychological studies and methodological issues. Neuropsychology 7(4):445463. https://doi.org/10.1037/0894-4105.7.4.445

Costalunga G, Kobylkov D, Rosa-Salva O, Vallortigara G, Mayer U (2021) Light-incubation effects on lateralisation of single unit responses in the visual Wulst of domestic chicks. Brain Struct Funct. https://doi.org/10.1007/s00429-021-02259-y

Eichert N, Watkins KE, Mars RB, Petrides M (2021) Morphological and functional variability in central and subcentral motor cortex of the human brain. Brain Struct Funct 226(1):263-279. https:// doi.org/10.1007/s00429-020-02180-w

Forkel SJ, Thiebaut de Schotten M, Dell'Acqua F, Kalra L, Murphy DG, Williams SC, Catani M (2014) Anatomical predictors of aphasia recovery: a tractography study of bilateral perisylvian language networks. Brain 137(Pt 7):2027-2039. https://doi.org/ 10.1093/brain/awu113.awu113[pii]

Forkel SJ, Friedrich P, Thiebaut de Schotten M, Howells H (2021) White matter variability, cognition, and disorders: a systematic review. Brain Struct Funct. https://doi.org/10.1007/ s00429-021-02382-w

Friedrich P, Patil K, Mochalski L, Li X, Camilleri J, Kröll J, Wiersch L, Eickhoff S, Weis S (in press) Is it left or is it right? A classification approach for investigating hemispheric differences in low- and high-dimensionality. Brain Struct Funct

Gainotti G (2019) The role of the right hemisphere in emotional and behavioral disorders of patients with frontotemporal lobar degeneration: an updated review. Front Aging Neurosci 11:55. https:// doi.org/10.3389/fnagi.2019.00055

Gallina J, Pietrelli M, Zanon M, Bertini C (2021) Hemispheric differences in altered reactivity of brain oscillations at rest after posterior lesions. Brain Struct Funct. https://doi.org/10.1007/ s00429-021-02279-8

Gerrits R, Verhelst H, Dhollander T, Xiang L, Vingerhoets G (2021) Structural perisylvian asymmetry in naturally occurring atypical language dominance. Brain Struct Funct. https://doi.org/10.1007/ s00429-021-02323-7

Geschwind N, Levitsky W (1968) Human brain: left-right asymmetries in temporal speech region. Science 161(837):186-187

Gomez-Ramirez J, Gonzalez-Rosa JJ (2021) Intra- and interhemispheric symmetry of subcortical brain structures: a volumetric analysis in the aging human brain. Brain Struct Funct. https://doi. org/10.1007/s00429-021-02305-9

Gonzalez Alam T, McKeown BLA, Gao Z, Bernhardt B, Vos de Wael R, Margulies DS, Smallwood J, Jefferies E (2021) A tale of two gradients: differences between the left and right hemispheres predict semantic cognition. Brain Struct Funct. https://doi.org/10. 1007/s00429-021-02374-w

Gonzalez P, Vallejo-Azar M, Aristide L, Lopes R, dos Reis SF, Perez SI (in press) Brain lateralization, endocranial shape, geometric morphometrics, home range size, group size, primates. Brain Struct Funct

Guadalupe T, Kong XZ, Akkermans SEA, Fisher SE, Francks C (2021) Relations between hemispheric asymmetries of grey matter and auditory processing of spoken syllables in 281 healthy adults. Brain Struct Funct. https://doi.org/10.1007/s00429-021-02220-z

Hadziselimovic H, Ruzdic N (1966) Appearance of the base of the brain in relation to the configuration of human skull. Acta Anat (Basel) 65(1):146-156

Ioannucci S, George N, Friedrich P, Cerliani L, Thiebaut de Schotten M (2020) White matter correlates of hemi-face dominance in happy and sad expression. Brain Struct Funct 225(4):1379-1388. https:// doi.org/10.1007/s00429-020-02040-7

Karolis VR, Corbetta M, Thiebaut de Schotten M (2019) The architecture of functional lateralisation and its relationship to callosal connectivity in the human brain. Nat Commun 10(1):1417. https:// doi.org/10.1038/s41467-019-09344-1

Liu J, Spagna A, Bartolomeo P (2021) Hemispheric asymmetries in visual mental imagery. Brain Struct Funct. https://doi.org/10. 1007/s00429-021-02277-w

Mazoyer B, Zago L, Jobard G, Crivello F, Joliot M, Perchey G, Mellet E, Petit L, Tzourio-Mazoyer N (2014) Gaussian mixture modeling of hemispheric lateralization for language in a large sample of healthy individuals balanced for handedness. PLoS One 9(6):e101165. https://doi.org/10.1371/journal.pone.0101165

McManus IC (2002) Right hand, left hand: the origins of asymmetry in brains, bodies, atoms, and cultures. Harvard University Press, Cambridge, Mass

Mills C (1912) The cerebral mechanisms of emotional expression. Trans Coll Phys Phila 34:381-390

Ocklenburg S et al (2021) Polygenic scores for handedness and their association with asymmetries in brain structure. Brain Struct Funct. https://doi.org/10.1007/s00429-021-02335-3

Palomero-Gallagher N, Amunts K (2021) A short review on emotion processing: a lateralized network of neuronal networks. Brain Struct Funct. https://doi.org/10.1007/s00429-021-02331-7

Ringo JL, Doty RW, Demeter S, Simard PY (1994) Time is of the essence: a conjecture that hemispheric specialization arises from interhemispheric conduction delay. Cereb Cortex 4(4):331-343. https://doi.org/10.1093/cercor/4.4.331

Rossion B, Lochy A (2021) Is human face recognition lateralized to the right hemisphere due to neural competition with left-lateralized visual word recognition? A critical review. Brain Struct Funct. https://doi.org/10.1007/s00429-021-02370-0

Silberman EK, Weingartner H (1986) Hemispheric lateralization of functions related to emotion. Brain Cogn 5(3):322-353. https:// doi.org/10.1016/0278-2626(86)90035-7

Sperry RW (1974) Lateral specialization in the surgically separated hemispheres. The Neurosciences. 3rd study program. Rockefeller University Press, New York

Sperry RW (1981) Roger W. Sperry-Nobel Lecture, 8 December 1981. The Nobel Prize. https://www.nobelprize.org/prizes/medic ine/1981/sperry/25059-roger-w-sperry-nobel-lecture-1981/.

Sprung-Much T, Eichert N, Nolan E, Petrides M (2021) Broca's area and the search for anatomical asymmetry: commentary and perspectives. Brain Struct Funct. https://doi.org/10.1007/ s00429-021-02357-x 
Takemura H, Thiebaut de Schotten M (2020) Perspectives given by structural connectivity bridge the gap between structure and function. Brain Struct Funct 225(4):1189-1192. https://doi.org/10. 1007/s00429-020-02080-z

Thiebaut de Schotten M, Shallice T (2017) Identical, similar or different? Is a single brain model sufficient? Cortex 86:172-175. https:// doi.org/10.1016/j.cortex.2016.12.002

Thiebaut de Schotten M, Friedrich P, Forkel SJ (2019) One size fits all does not apply to brain lateralisation: Comment on "Phenotypes in hemispheric functional segregation? Perspectives and challenges" by Guy Vingerhoets. Phys Life Rev 30:30-33. https://doi.org/10. 1016/j.plrev.2019.07.007

Thiebaut de Schotten M, Foulon C, Nachev P (2020) Brain disconnections link structural connectivity with function and behaviour. Nat Commun 11(1):5094. https://doi.org/10.1038/ s41467-020-18920-9

Toga AW, Thompson PM (2003) Mapping brain asymmetry. Nat Rev Neurosci 4(1):37-48. https://doi.org/10.1038/nrn1009

Vallesi A, Visalli A, Gracia-Tabuenca Z, Tarantino V, Capizzi M, Alcauter S, Mantini D, Pini L (2021) Fronto-parietal homotopy in resting-state functional connectivity predicts task-switching performance. Brain Struct Funct. https://doi.org/10.1007/ s00429-021-02312-w
Vallortigara G, Rogers LJ (2005) Survival with an asymmetrical brain: advantages and disadvantages of cerebral lateralization. Behav Brain Sci 28(4):575-589. https://doi.org/10.1017/S0140525X0 5000105 (discussion 589-633)

Vingerhoets G (2019) Phenotypes in hemispheric functional segregation? Perspectives and challenges. Phys Life Rev 30:1-18. https:// doi.org/10.1016/j.plrev.2019.06.002

Wada JA, Clarke R, Hamm A (1975) Cerebral hemispheric asymmetry in humans. Cortical speech zones in 100 adults and 100 infant brains. Arch Neurol 32(4):239-246. https://doi.org/10.1001/archn eur.1975.00490460055007

Westerhausen R, Papadatou-Pastou M (in press) Handedness and midsagittal corpus callosum morphology: a systematic meta-analytic evaluation. Brain Struct Funct

Yakovlev PJ, Rakic P (1966) Pattern of decussation of bulbar pyramids and distribution of pyramidal tracts on two sides of the spinal cord. Trans Amer Neurol Assoc 91:366-367

Publisher's Note Springer Nature remains neutral with regard to jurisdictional claims in published maps and institutional affiliations. 